\title{
Association between halitosis and female fecundability in China: a prospective cohort study
}

Xiaona Huo ${ }^{1,2 \dagger}$, Lin Zhang ${ }^{3 \dagger}$, Rong Huang ${ }^{2}$, Jiangfeng Ye ${ }^{2}$, Yulin Yang ${ }^{4}$, Hao Zhang ${ }^{5 *}$ and Jun Zhang ${ }^{2,6^{*}}$

\begin{abstract}
Background: Periodontal diseases and poor oral hygiene are potentially associated with decreased female fecundability. Fecundability refers to the probability of conception during a given period measured in months or menstrual cycles. This study aims to examine whether halitosis is associated with female fecundability in a large sample of Chinese women who planned to be pregnant.

Methods: In 2012, a total of 6319 couples came for preconception care in eight districts in Shanghai, China and were followed by telephone contact. Three thousand nine hundred fifteen women who continued trying to be pregnant for up to 24 months remained for final statistical analyses. Halitosis was self-reported at the preconception care visit. Time to pregnancy (TTP) was reported in months and was censored at 24 months. Fecundability ratio (FR) was defined as the ratio of probability of conception among those with and without halitosis. FR and 95\% confidence interval (Cl) were estimated using the discrete-time Cox model.

Results: 80.1 and $86.1 \%$ of women had self-reported clinically confirmed pregnancy within 12 and 24 months, respectively. Halitosis was reported in $8.7 \%$ of the women. After controlling for potential confounders, halitosis was associated with a reduced probability of spontaneous conception (for an observation period of 12 months: adjusted FR 0.82, 95\% Cl 0.72-0.94; for an observation period of 24 months: adjusted FR 0.84, 95\% Cl 0.74-0.96).
\end{abstract}

Conclusions: Halitosis is associated with reduced fecundability in Chinese women.

Keywords: Halitosis, Oral hygiene, Oral health, Fecundability, Time to pregnancy

\section{Background}

Time to pregnancy (TTP) defined as the time from removing the contraceptive measures to achieving conception with timely intercourse, has been widely used as an informative measure of couple fertility in epidemiological studies [1]. A TTP longer than 12 months is a

*Correspondence: haozhang18@foxmail.com; junjimzhang@sina.com

${ }^{+}$Xiaona Huo and Lin Zhang are considered as co-first authors.

${ }^{2}$ MOE-Shanghai Key Laboratory of Children's Environmental Health,

Xinhua Hospital, Shanghai Jiao Tong University School of Medicine, 1665 Kong Jiang Road, Shanghai 200092, China

${ }^{5}$ Department of Preventive Dentistry, Shanghai Stomatological Hospital,

Fudan University, 356 East Beijing Road, Shanghai 200001, China

Full list of author information is available at the end of the article usual cut-off to define infertility [2] though a 24-month cut-off of TTP for infertility is also used [3]. Infertility is defined as couples having had unprotected sex but failed to conceive naturally for 12 or 24 months [2, 3]. Extensive evidence has shown that advanced woman's age, smoking, drinking, obesity, endocrine disorders and environmental factors are associated with prolonged TTP and infertility [4-8].

Recently, three epidemiologic studies suggested that periodontal diseases (PD) and poor oral hygiene were also associated with increased TTP [9-11]. It was postulated that bad oral health may exert adverse endometrial effects through systemic inflammation [9]. However, little 
is known about the association between oral health problems and TTP in Asian populations.

Halitosis, commonly called "bad breath" or "oral malodor", is defined as an unpleasant or offensive odor mostly arising from the oral cavity $[12,13]$. It is prevalent worldwide and affects all ages $[14,15]$. More than $80 \%$ of the cases had intra-oral causes a, such as poor oral hygiene, gingivitis, periodontitis and dry mouth [13, 16-18]. Keeping clean and healthy oral conditions, as well as periodontal treatment have been shown to be the most basic and effective methods to prevent and reduce halitosis [19]. Therefore, we hypothesize that halitosis might be a proxy for overall poor oral health. This study aimed to investigate the association between halitosis and female fecundability in a prospective study in Chinese women.

\section{Methods}

\section{Study design and study population}

In recent years, the Chinese government has been promoting preconception care for couples who plan to be pregnant. In the Shanghai municipality, China, each district has a designated preconception care clinic usually located in a maternity care facility. Registered residents in the corresponding district may obtain a voucher from their community to receive free care in the designated clinic. At the visit, couples are first informed by health care workers on the purpose and procedures involved in the preconception care and are asked to sign a consent form. Information on demographic characteristics, medical history, family history, health behavior and lifestyle are collected. Physicians conduct a physical examination on the couples. Routine blood and urine tests are performed. Couples are provided with health education on how to prepare a healthy pregnancy such as folate supplementation and smoking cessation. After the blood and urine test results are obtained, physicians provide a risk assessment and counseling to the couple. Women are contacted by health care workers via telephone calls at 3, 6, 12 and 24 months after the care encounter. If a woman becomes pregnant, information on pregnancy and pregnancy outcomes is collected. Women were asked "Have you had a clinically diagnosed pregnancy? For how many months have you tried to conceive?"

Eight out of 17 Shanghai districts were randomly selected in an evaluation study by the municipal government. The purpose of the study was to evaluate the benefits and effectiveness of the free preconception care program. The current analysis utilized the data from the evaluation study.

From January 2012 to December 2012, a total of 6319 couples sought preconception care at these clinics. Exclusion criteria were couples who 1) had infertility history; 2) were lost to follow-up; 3) changed the pregnancy plan; 4) were diagnosed with male infertility; 5) accepted assisted reproductive technology; 6) had missing data on oral malodor; 7) had missing data on TTP. Figure 1 illustrates the sample selection process. In the end, 3915 couples remained for final analyses. Among them, 3369 $(86.1 \%)$ women had given birth or were pregnant at the time of the final follow-up at 24 months while 546 (13.9\%) women had not been pregnant during the entire followup period. This study was approved by the Ethics Committee of Xinhua Hospital Affiliated to Shanghai Jiao Tong University School of Medicine, Shanghai, China.

\section{Measures}

Halitosis was a self-reported item in the questionnaire with responses of yes/no. Halitosis refers to unpleasant odor currently originating from mouth that was detected by herself or others, or diagnosed clinically, and regardless of whether it was acute or chronic. The outcome was natural conception within the status of pregnancy at 12 and 24 months. TTP was defined as the number of months that a couple were trying to conceive spontaneously.

\section{Statistical analysis}

Bivariate analyses were conducted to assess the association between socio-demographic characteristics and halitosis by Chi-square tests and Mann-Whitney U tests. Therefore, fecundability ratio (FR) and $95 \%$ confidence interval (CI) for halitosis were calculated in the Cox proportional hazard model for discrete-time survival analysis. A FR $<1$ represents reduction in fecundability, and a FR $>1$ represents higher fecundability. The TTP was censored at 12 or 24 months in the corresponding analyses, respectively.

A set of potential confounders were selected based on a directed acyclic graph (DAG, Supplementary Fig. 1) in consideration of previous reports [12], including female age at preconception care $(<25,25-30,30-35,35-40, \geq$ 40 years), BMI at preconception care $(<18.5,18.5-24.9$, $\left.25-29.9, \geq 30 \mathrm{~kg} / \mathrm{m}^{2}\right)$, indicators of socioeconomic status (female occupation [teachers, civil servants and businessmen; farmers, workers and waiter; housewife or others] and education level $[\leq 9,10-12,13-16, \geq 17$ years $]$ ), smoking status (yes, no, unknown), alcohol consumption (yes, no, unknown), diet (dislike to eat vegetables and like to eat raw meat), indicators of psychological stress (perceived life or work-related stress; tension with relatives, friends or colleagues; and financial pressure), medical history (including anemia, hypertension, heart disease, diabetes, thyroid disease, chronic nephritis, tumor, tuberculosis and hepatitis B; yes, no) and gingival bleeding (yes, no, unknown). Fully conditional specification (FCS) methods of multiple imputation was applied to deal with 


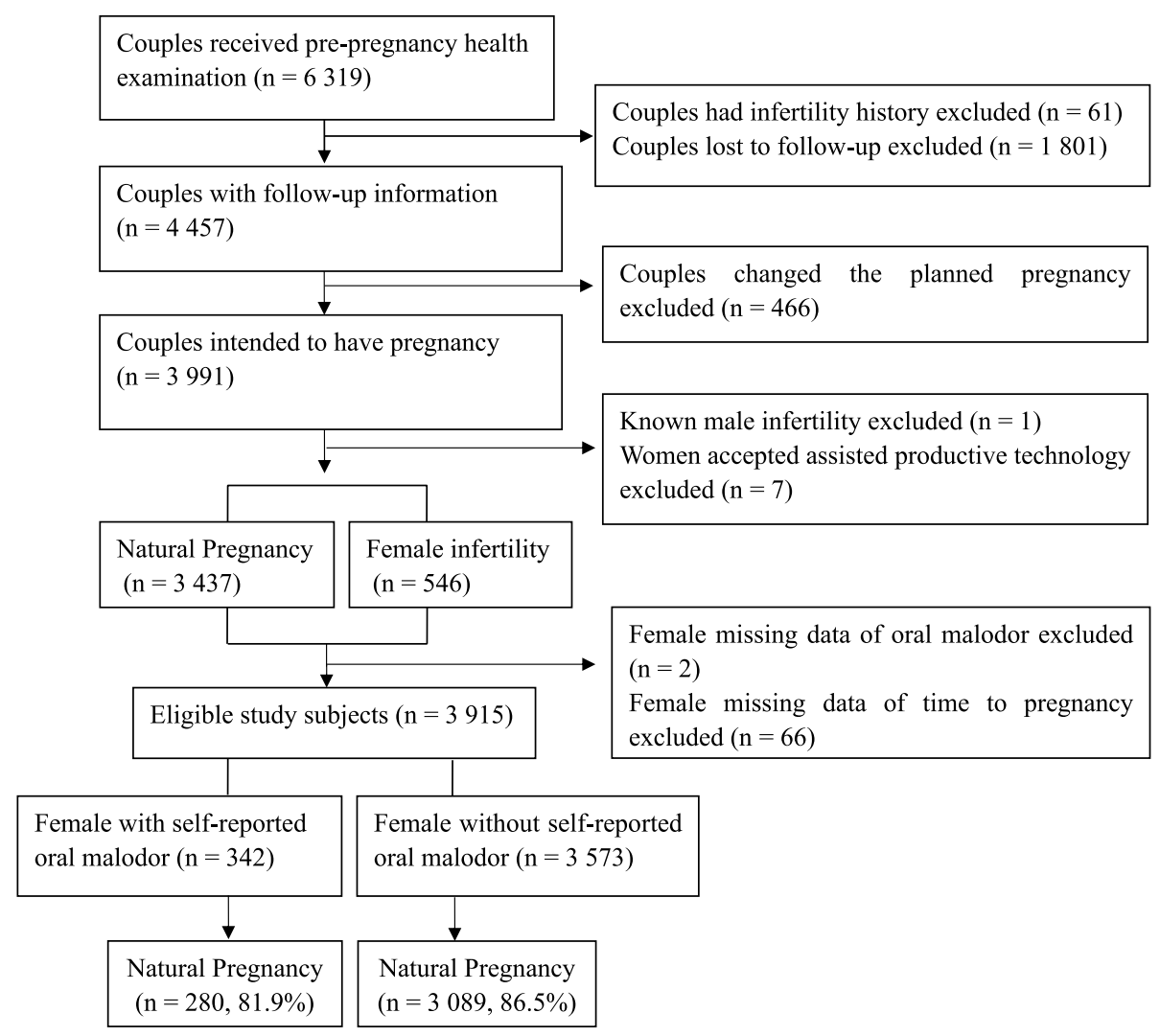

Fig. 1 Study Flow Chart

the missing data for confounders [20,21]. To rule out the potential modification effect of chronic inflammation due to periodontal disease on the association of interest, we conducted subgroup analyses by stratifying whether a woman had frequent gingival bleeding. Kaplan-Meier survival curves and log-rank test were used to assess the bivariate association between halitosis and fecundability within 24 months. All statistical analyses were conducted using SAS version 9.4 (SAS Institute Inc., Cary, NC, USA).

\section{Results}

Among the 3915 women, 3136 (80.1\%) and 3369 (86.1\%) became pregnant within 12 and 24 months, respectively. The prevalence of self-reported halitosis was $8.7 \%$. The mean age of these women was 28.0 (range 20-49) years. The vast majority was Han ethnicity $(98.7 \%)$ and had normal weight $(73.1 \%)$. Those with self-reported halitosis had a lower level of education, and were more likely to smoke, drink, dislike to eat vegetable, and like to eat raw meat. They were also more likely to perceive a higher level of life or work-related stress and financial pressure, have a tense relationship with relatives, friends or colleagues, and a higher prevalence of gingival bleeding (Table 1). They had a slightly longer TTP. 73.1\% of women in the halitosis group reported a clinically confirmed pregnancy by 12 months, while $80.8 \%$ did so in the non-halitosis group.

Table 2 shows that compared with women without halitosis, those with halitosis had reduced fecundability in the observation period of 12 months (adjusted FR 0.82, 95\% CI 0.72-0.94) and 24months (adjusted FR 0.84, 95\% CI 0.74-0.96) after controlling for potential confounders. Figure 2 shows that women without halitosis were quicker to become pregnant. Stratified analyses by gingival bleeding further showed that halitosis was associated with decreased fecundability regardless of gingival bleeding (Table 3).

\section{Discussion}

Our study shows that among Chinese women in Shanghai who planned to be pregnant, 80.1 and $86.1 \%$ became pregnant within 12 and 24 months, respectively. We also found that halitosis was negatively associated with female fecundability. Our study was consistent with the other three studies that reported an association of poor oral health and periodontal diseases and prolonged TTP. A case-control study involving 58 non-pregnant women 
Table 1 Baseline characteristics of women by halitosis status, $N=3915$

\begin{tabular}{|c|c|c|}
\hline & Halitosis $N=342$ & $\begin{array}{l}\text { Non - } \\
\text { halitosis } \\
N=3573\end{array}$ \\
\hline \multicolumn{3}{|l|}{ Ethnicity } \\
\hline Han & $337(98.5)$ & $3535(98.9)$ \\
\hline Others & $5(1.5)$ & $38(1.1)$ \\
\hline \multicolumn{3}{|l|}{ Age at preconception care (years) } \\
\hline$<25$ & $45(13.2)$ & $409(11.5)$ \\
\hline $25-29$ & $181(52.9)$ & $2083(58.3)$ \\
\hline $30-34$ & $106(31.0)$ & $952(26.6)$ \\
\hline $35-39$ & $10(3.0)$ & $111(3.1)$ \\
\hline$\geq 40$ & $0(0.0)$ & $18(0.5)$ \\
\hline \multicolumn{3}{|l|}{ Educational level (years) } \\
\hline$\leq 9$ & $13(3.8)$ & $114(3.2)$ \\
\hline $10-12$ & $41(12.0)$ & $367(10.3)$ \\
\hline $13-16$ & $268(78.4)$ & $2730(76.4)$ \\
\hline$\geq 17$ & $20(5.9)$ & $362(10.1)$ \\
\hline \multicolumn{3}{|l|}{ Occupation } \\
\hline Teachers, civil servants and businessmen & $161(47.1)$ & $1791(50.1)$ \\
\hline Farmers, workers and waiter & $43(12.6)$ & $486(13.6)$ \\
\hline Housework or others & $138(40.4)$ & $1296(36.3)$ \\
\hline \multicolumn{3}{|l|}{ BMI at preconception care $\left(\mathrm{kg} / \mathrm{m}^{2}\right)^{\mathrm{a}}$} \\
\hline$<18.5$ & $73(21.4)$ & $676(18.9)$ \\
\hline $18.5-24.9$ & $240(70.2)$ & $2622(73.4)$ \\
\hline $25-29.9$ & $23(6.7)$ & $220(6.2)$ \\
\hline$\geq 30$ & $1(0.3)$ & $38(1.1)$ \\
\hline Unknown & $5(1.5)$ & $17(0.5)$ \\
\hline \multicolumn{3}{|l|}{ Smoking status } \\
\hline Never & $329(96.2)$ & $3542(99.1)$ \\
\hline Yes & $13(3.8)$ & $30(0.8)$ \\
\hline Unknown & $0(0.0)$ & $1(0.03)$ \\
\hline \multicolumn{3}{|l|}{ Alcohol consumption } \\
\hline Never & $246(71.9)$ & $2859(80.0)$ \\
\hline Occasionally & $91(26.6)$ & $689(19.3)$ \\
\hline Frequently & $5(1.5)$ & $19(0.5)$ \\
\hline Unknown & $0(0.0)$ & $6(0.2)$ \\
\hline \multicolumn{3}{|l|}{ Dislike to eat vegetables } \\
\hline No & $319(93.3)$ & $3462(96.9)$ \\
\hline Yes & $23(6.7)$ & $111(3.1)$ \\
\hline \multicolumn{3}{|l|}{ Like to eat raw meat } \\
\hline No & $316(92.4)$ & $3453(96.6)$ \\
\hline Yes & $26(7.6)$ & $120(3.4)$ \\
\hline \multicolumn{3}{|l|}{ Perceived life or work-related stress } \\
\hline No & $58(17.0)$ & $917(25.7)$ \\
\hline Yes & $284(83.0)$ & $2656(74.3)$ \\
\hline \multicolumn{3}{|l|}{ Tension with relatives, friends or colleagues } \\
\hline No & $222(64.9)$ & $2830(79.2)$ \\
\hline Yes & $120(35.1)$ & $743(20.8)$ \\
\hline \multicolumn{3}{|l|}{ Feeling of financial pressure } \\
\hline No & $136(39.8)$ & $1848(51.7)$ \\
\hline Yes & $206(60.2)$ & $1725(48.3)$ \\
\hline
\end{tabular}


Table 1 (continued)

\begin{tabular}{|c|c|c|}
\hline & Halitosis $N=342$ & $\begin{array}{l}\text { Non - } \\
\text { halitosis } \\
N=3573\end{array}$ \\
\hline \multicolumn{3}{|c|}{ Medical history ${ }^{b}$} \\
\hline No & $272(79.5)$ & $3093(86.6)$ \\
\hline Yes & $70(20.5)$ & $480(13.4)$ \\
\hline \multicolumn{3}{|c|}{ Gingival bleeding } \\
\hline No & $105(40.7)$ & $2239(62.7)$ \\
\hline Yes & $178(52.0)$ & $892(25.0)$ \\
\hline Unknown & $59(17.3)$ & $442(12.4)$ \\
\hline \multicolumn{3}{|c|}{ Time-to-pregnancy [observation period $=12$ months; Median $(\mathrm{p} 25, \mathrm{p} 75)$ ] } \\
\hline & $6(3,12)$ & $6(2,12)$ \\
\hline \multicolumn{3}{|c|}{ Time-to-pregnancy [observation period = 24 months; Median (p25, p75)] } \\
\hline & $6(3,18)$ & $6(3,12)$ \\
\hline
\end{tabular}

a BMI: body mass index; raw meat: meat is not cooked such as sashimi

${ }^{\mathrm{b}}$ Medical history: anemia, hypertension, heart disease, diabetes, thyroid disease, chronic nephritis, tumour, tuberculosis, hepatitis B

Table 2 Multivariate survival analysis of the association between halitosis and time to pregnancy

\begin{tabular}{|c|c|c|c|c|c|c|c|c|c|c|}
\hline \multirow{2}{*}{$\begin{array}{l}\text { Exposure } \\
\text { Categories }\end{array}$} & \multicolumn{5}{|c|}{ Observation period $=12$ months } & \multicolumn{5}{|c|}{ Observation period $=24$ months } \\
\hline & Pregnancy n (\%) & FR & $95 \% \mathrm{Cl}$ & $\mathrm{a}_{\mathrm{aFR}}$ & $95 \% \mathrm{Cl}$ & Pregnancy n (\%) & FR & $95 \% \mathrm{Cl}$ & $\mathrm{a}_{\mathrm{aFR}}$ & $95 \% \mathrm{Cl}$ \\
\hline \multicolumn{11}{|l|}{ Halitosis } \\
\hline No & $2886(80.8)$ & Ref & 1 & Ref & 1 & $3089(86.5)$ & Ref & 1 & Ref & 1 \\
\hline Yes & $250(73.1)$ & 0.84 & $0.74-0.95$ & 0.82 & $0.72-0.94$ & $280(81.9)$ & 0.86 & $0.76-0.97$ & 0.84 & $0.74-0.96$ \\
\hline
\end{tabular}

Abbreviation: $a F R$ adjusted fecundability ratio

a adjusting for female age at preconception care (years), BMI at preconception care $\left(\mathrm{kg} / \mathrm{m}^{2}\right)$, female occupation (teachers, civil servants and businessmen (reference); farmers, workers and waiter; housewife or others), education level (years), smoking status (no, yes), alcohol consumption (no, occasional, frequent, unknown), dislike to eat vegetables (no, yes), like to eat raw meat (no, yes), perceived life or work -related stress (no, yes), tension with relatives, friends or colleagues (no, yes), financial pressure (no, yes), medical history (no, yes), gingival bleeding (no, yes)

and 70 pregnant women reported that women with good oral hygiene were more likely to be pregnant within 1 year in African American women [10]. A very recent large prospective cohort study in North America indicated a significant association between a self-reported history of periodontitis and decreased fecundability [11]. Hart et al. reported similar results that periodontal disease was associated with prolonged TTP in non-Caucasian (67.1\% were Asian and the others were African, Aboriginal, and other ethnicities) women in Australia. But there was no significant association in Caucasian women [9]. The researchers attributed the observed ethnic disparity to the single nucleotide polymorphisms related to periodontal disease [9]. The ethnic disparity in the ability to mount inflammatory/immune responses [9] might be another possible reason. Furthermore, ethnicity might be a proxy for diet, cultural practices, barriers to healthcare access or other structural factors that may affect oral health and fertility.

Microorganisms, especially anaerobic bacteria, are the main cause of bad breath and PD [16-18, 22]. Previous studies showed that oral flora can go through uterine cavity, amnion cavity, placenta, and even fetus, and has been suggested to be an important risk factor for recurrent miscarriage, intrauterine death, preterm birth and neonatal death [23-26]. For example, Porphyromonas gingivalis, which plays an important role in the development of halitosis, was found in both periodontal pocket and amniotic fluid of women at high-risk of premature labor [25]. A recent study found that Porphyromonas gingivalis infection in female genital tract was associated with recurrent miscarriages [24]. Elevated levels of inflammatory mediators in saliva and some mediators in serum have been found among pre-conception women with periodontal disease [27].

Oral bacteria are also found to be associated with infection at extra-oral locations, such as lung, vasculature and pancreas [28-30]. Bacterial pathogens could activate a cascade of tissue-destructive pathways [31, 32] and elevated systemic levels of cytokines such as tumor necrosis factor alpha, which could lead to chronic systemic inflammation [33]. Such low-grade systemic 


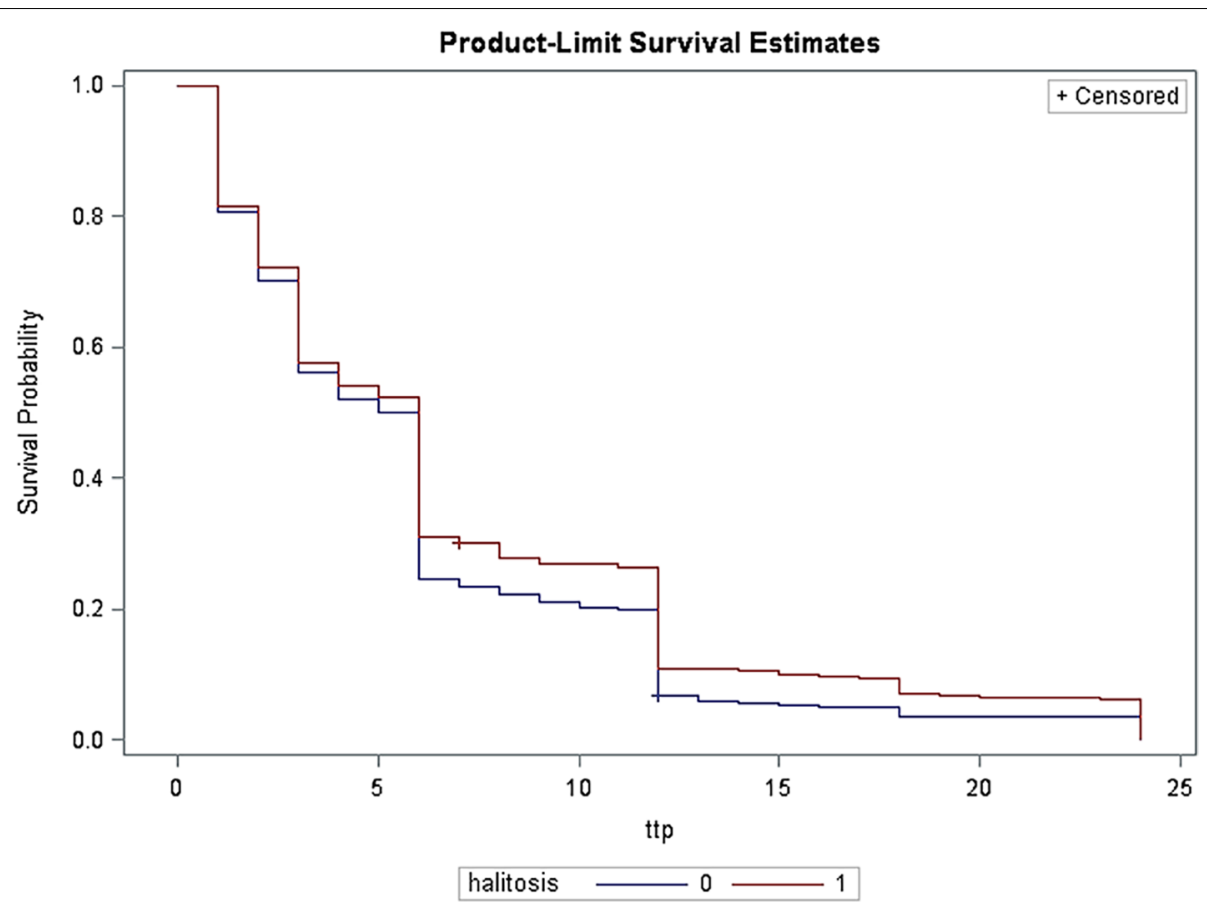

Fig. 2 Kaplan-Meier curve for time to pregnancy according to halitosis (yes was recorded as 1, and otherwise 0). Quicker to get pregnant is indicated for women without halitosis (Log-Rank $P=0.02)$

Table 3 Multivariate survival analysis of the association between halitosis and time to pregnancy stratified by gingival bleeding status

\begin{tabular}{|c|c|c|c|c|c|c|c|c|}
\hline \multirow[b]{2}{*}{ Exposure Categories } & \multicolumn{4}{|c|}{ Observation period $=12$ months } & \multicolumn{4}{|c|}{ Observation period $=24$ months } \\
\hline & FR & $95 \% \mathrm{Cl}$ & ${ }^{a} \mathrm{aFR}$ & $95 \% \mathrm{Cl}$ & FR & $95 \% \mathrm{Cl}$ & ${ }^{\mathrm{a} a F R}$ & $95 \% \mathrm{Cl}$ \\
\hline \multicolumn{9}{|l|}{ Non- Gingival bleeding } \\
\hline Non-Halitosis & Ref & 1 & Ref & 1 & Ref & 1 & Ref & 1 \\
\hline Halitosis & 0.84 & $0.69-1.03$ & 0.81 & $0.66-0.995$ & 0.88 & $0.73-1.06$ & 0.85 & $0.70-1.03$ \\
\hline \multicolumn{9}{|l|}{ Gingival bleeding } \\
\hline Non-Halitosis & Ref & 1 & Ref & 1 & Ref & 1 & Ref & 1 \\
\hline Halitosis & 0.81 & $0.68-0.98$ & 0.83 & $0.69-1.00$ & 0.82 & $0.69-0.97$ & 0.84 & $0.70-1.00$ \\
\hline
\end{tabular}

Abbreviation: $a F R$ adjusted fecundability ratio

a adjusting for female age at preconception care (years), BMI at preconception care $\left(\mathrm{kg} / \mathrm{m}^{2}\right)$, female occupation (teachers, civil servants and businessmen (reference); farmers, workers and waiter; housewife or others), education level (years), smoking status (no, yes), alcohol consumption (no, occasional, frequent, unknown), dislike to eat vegetables (no, yes), like to eat raw meat (no, yes), perceived life or work -related stress (no, yes), tension with relatives, friends or colleagues (no, yes), financial pressure (no, yes), medical history (no, yes)

inflammation is thought to present an endometrial effect similar to endometriosis [10,34], which could negatively affect fertility and conception. Thus, it is reasonable to hypothesize that increased oral pathogenic bacteria might circulate through bloodstream, enter reproductive organ, and then, result in reduced fecundability [24, 25, 35].

The present study found a lower prevalence of halitosis $(8.7 \%)$ in reproductive age women than those in general adult populations in Beijing (27.8\%) and Shanghai (33\%) $[15,36]$. This difference in prevalence may be due to several factors. First, the previous studies measured organoleptic measurements or volatile sulphide compounds, respectively $[15,36]$, which were likely to be more sensitive than self-report in our study. Thus, some women may have been misclassified in our study. Second, the study populations differed. Our subjects were reproductive-age women, but the subjects in the other studies covered a diverse population $[15,35]$. It has been reported that halitosis was more common in those who were older and perceived more stress, but less common in younger females [37, 38]. Iwakura et al. [39] suggested 
that a person who has halitosis may be accompanied by decreased olfactory function. Thus, underreporting of halitosis in these women is possible. Women may also feel ashamed to report halitosis. However, this was a prospective study. If halitosis is truly associated with infertility, underreporting of halitosis may have drawn our results towards the null to an unknown degree.

Our study was also limited by its inability to explore the underlying causes of halitosis; neither can we prove a cause-and-effect relationship. The self-reported halitosis might be an indicator of bad oral health, or symptoms of other medical conditions and illness, including diabetes, or unhealthy behaviors such as smoking and drinking $[4,15]$. However, the significant association remained after we had adjusted for these factors in the multivariable model. We did not have the information on quantity of alcohol consumption, which was a limitation of our study. Thus, the results of our study should be interpreted with caution. Future studies are warranted to explore the underlying mechanisms between the association between halitosis and fecundability.

In addition, $28.5 \%$ of subjects were lost to follow-up. We compared women who were lost and who remained in this study. There was no significant difference between these two groups in the prevalence of halitosis (9.2 vs. 8.7, respectively). Thus, the loss-to-follow-up was unlikely to be differential.

\section{Conclusions}

Our large prospective cohort study showed that selfreported halitosis was associated with reduced fecundability in Chinese women who plan to become pregnant. More research is warranted to identify modifiable factors and implement effective prevention strategies to reduce the risk of infertility.

\section{Abbreviations}

Cl: Confidence interval; FR: Fecundability ratio; PD: Periodontal diseases; TTP: Time to pregnancy.

\section{Supplementary Information}

The online version contains supplementary material available at https://doi. org/10.1186/s12884-021-04315-1.

Additional file 1: Supplementary Figure 1. Directed acyclic graph illustrated confounders. BMI, body mass index; SES, socioeconomic status.

\section{Acknowledgments}

We thank Dr. Stella Yu for her helpful comments on this manuscript.

\section{Authors' contributions}

$X$ Huo designed the study, analyzed the data and drafted the manuscript. L Zhang and R Huang helped to revise the manuscript. J Ye and Y Yang participated in the evaluation study and provided critical feedback on manuscript drafts. J Zhang and $\mathrm{H}$ Zhang were the Principle Investigators of the project, helped draft the manuscript, critically revised and approved the final version. All authors have reviewed the final version of the manuscript and agreed the submission for publication.

\section{Funding}

This study was supported by the Shanghai Municipal Health Commission (GWV-10.1-XK07).

\section{Availability of data and materials}

All data generated or analyzed during this study are included in this published article.

\section{Declarations}

Ethics approval and consent to participate

This study was approved by the Ethics Committee of Xinhua Hospital Affiliated to Shanghai Jiao Tong University School of Medicine, Shanghai, China. All participants signed an informed consent. All methods were carried out in accordance with relevant guidelines and regulations.

\section{Consent for publication}

Not applicable.

\section{Competing interests}

The authors declare that they have no competing interests.

\section{Author details}

${ }^{1}$ Obstetrics and Gynecology Department, International Peace Maternity and Child Health Hospital of China, Shanghai Jiao Tong University School of Medicine, Shanghai 200030, China. ${ }^{2}$ MOE-Shanghai Key Laboratory of Children's Environmental Health, Xinhua Hospital, Shanghai Jiao Tong University School of Medicine, 1665 Kong Jiang Road, Shanghai 200092, China. ${ }^{3}$ Obstetrics Department, International Peace Maternity and Child Health Hospital of China, Shanghai Jiao Tong University School of Medicine, Shanghai 200030, China. ${ }^{4}$ Department of Maternal and Child Health Care, Shanghai Municipal Health and Family Planning Commission, 300 Expo Village Road, Shanghai 200125, China. ${ }^{5}$ Department of Preventive Dentistry, Shanghai Stomatological Hospital, Fudan University, 356 East Beijing Road, Shanghai 200001,

China. ${ }^{6}$ Hainan Women and Children's Medical Center, Haiko, Hainan, China.

Received: 9 July 2021 Accepted: 1 December 2021

Published online: 20 December 2021

References

1. Snijder CA, te Velde E, Roeleveld N, Burdorf A. Occupational exposure to chemical substances and time to pregnancy: a systematic review. Hum Reprod Update. 2012;18(3):284-300.

2. Zegers-Hochschild F, Adamson GD, de Mouzon J, Ishihara O, Mansour R, Nygren K, et al. International Committee for Monitoring Assisted Reproductive Technology (ICMART) and the World Health Organization (WHO) revised glossary of ART terminology, 2009. Fertil Steril. 2009:92(5):1520-4.

3. Gurunath S, Pandian Z, Anderson RA, Bhattacharya S. Defining infertility-a systematic review of prevalence studies. Hum Reprod Update. 2011;17(5):575-88.

4. Mokeem SA. Halitosis: a review of the etiologic factors and association with systemic conditions and its management. J Contemp Dent Pract. 2014;15(6):806-11.

5. Tubaishat RS, Malkawi ZA, Albashaireh ZS. The influence of different factors on the oral health status of smoking and nonsmoking adults. J Contemp Dent Pract. 2013;14(4):731-7.

6. Wildenschild C, Riis AH, Ehrenstein V, Hatch EE, Wise LA, Rothman KJ, et al. A prospective cohort study of a woman's own gestational age and her fecundability. Hum Reprod. 2015;30(4):947-56.

7. Balen AH, Morley LC, Misso M, Franks S, Legro RS, Wijeyaratne CN, et al. The management of anovulatory infertility in women with polycystic 
ovary syndrome: an analysis of the evidence to support the development of global WHO guidance. Hum Reprod Update. 2016;22(6):687-708.

8. Bach CC, Vested A, Jorgensen KT, Bonde JP, Henriksen TB, Toft G. Perfluoroalkyl and polyfluoroalkyl substances and measures of human fertility: a systematic review. Crit Rev Toxicol. 2016;46(9):735-55.

9. Hart R, Doherty DA, Pennell CE, Newnham IA, Newnham JP. Periodontal disease: a potential modifiable risk factor limiting conception. Hum Reprod. 2012;27(5):1332-42.

10. Nwhator S, Opeodu O, Ayanbadejo P, Umeizudike K, Olamijulo J, Alade G, et al. Could periodontitis affect time to conception? Ann Med Health Sci Res. 2014;4(5):817-22

11. Bond JC, Wise LA, Willis SK, Yland JJ, Hatch EE, Rothman KJ, et al. Selfreported periodontitis and fecundability in a population of pregnancy planners. Hum Reprod. 2021;36(8):2298-308.

12. Seemann R, Conceicao MD, Filippi A, Greenman J, Lenton P, Nachnani S, et al. Halitosis management by the general dental practitioner-results of an international consensus workshop. J Breath Res. 2014;8(1):017101.

13. Delanghe G, Ghyselen J, van Steenberghe D, Feenstra L. Multidisciplinary breath-odour clinic. Lancet. 1997;350(9072):187.

14. Akaji EA, Folaranmi N, Ashiwaju O. Halitosis: a review of the literature on its prevalence, impact and control. Oral Health Prev Dent. 2014;12(4):297-304.

15. Liu XN, Shinada K, Chen XC, Zhang BX, Yaegaki K, Kawaguchi Y. Oral malodor-related parameters in the Chinese general population. J Clin Periodontol. 2006;33(1):31-6.

16. Tonzetich J. Production and origin of oral malodor: a review of mechanisms and methods of analysis. J Periodontol. 1977:48(1):13-20.

17. Kapoor U, Sharma G, Juneja M, Nagpal A. Halitosis: current concepts on etiology, diagnosis and management. Eur J Dent. 2016;10(2):292-300.

18. HajiFattahi F, Hesari M, Zojaji H, Sarlati F. Relationship of halitosis with gastric helicobacter pylori infection. J Dent (Tehran). 2015:12(3):200-5.

19. Suzuki $\mathrm{N}$, Yoneda M, Takeshita T, Hirofuji T, Hanioka T. Induction and inhibition of oral malodor. Mol Oral Microbiol. 2019;34(3):85-96.

20. Lee KJ, Carlin JB. Multiple imputation for missing data: fully conditional specification versus multivariate normal imputation. Am J Epidemiol. 2010;171(5):624-32.

21. Liu Y, De A. Multiple imputation by fully conditional specification for dealing with missing data in a large epidemiologic study. Int J Stat Med Res. 2015;4(3):287-95

22. Morita M, Wang HL. Relationship between sulcular sulfide level and oral malodor in subjects with periodontal disease. J Periodontol. 2001:72(1):79-84

23. Bieniek KW, Riedel HH. Bacterial foci in the teeth, oral cavity, and jaw-secondary effects (remote action) of bacterial colonies with respect to bacteriospermia and subfertility in males. Andrologia. 1993;25(3):159-62.

24. Ibrahim Ml, Abdelhafeez MA, Ellaithy MI, Salama AH, Amin AS, Eldakrory $\mathrm{H}$, et al. Can Porphyromonas gingivalis be a novel aetiology for recurrent miscarriage? Eur J Contracept Reprod Health Care. 2015;20(2):119-27.

25. Leon R, Silva N, Ovalle A, Chaparro A, Ahumada A, Gajardo M, et al. Detection of Porphyromonas gingivalis in the amniotic fluid in pregnant women with a diagnosis of threatened premature labor. J Periodontol. 2007;78(7):1249-55.

26. Bearfield C, Davenport ES, Sivapathasundaram V Allaker RP. Possible association between amniotic fluid micro-organism infection and microflora in the mouth. BJOG. 2002;109(5):527-33.

27. Jiang $H$, Zhang $Y$, Xiong $X$, Harville EW. O K, Qian X: salivary and serum inflammatory mediators among pre-conception women with periodontal disease. BMC Oral Health. 2016;16(1):131.

28. Scannapieco FA. Pneumonia in nonambulatory patients. The role of oral bacteria and oral hygiene. J Am Dent Assoc. 2006;137(Suppl):21S-5S.

29. Michaud DS, Izard J, Wilhelm-Benartzi CS, You DH, Grote VA, Tjonneland A, et al. Plasma antibodies to oral bacteria and risk of pancreatic cancer in a large European prospective cohort study. Gut. 2013;62(12):1764-70.

30. Boillot A, Demmer RT, Mallat Z, Sacco RL, Jacobs DR, Benessiano J, et al. Periodontal microbiota and phospholipases: the Oral infections and vascular disease epidemiology study (INVEST). Atherosclerosis. 2015;242(2):418-23.

31. Williams RC, Barnett AH, Claffey N, Davis M, Gadsby R, Kellett M, et al. The potential impact of periodontal disease on general health: a consensus view. Curr Med Res Opin. 2008;24(6):1635-43.
32. Kebschull M, Demmer RT, Papapanou PN. "Gum bug, leave my heart alone!"--epidemiologic and mechanistic evidence linking periodontal infections and atherosclerosis. J Dent Res. 2010;89(9):879-902.

33. An LF, Zhang XH, Sun XT, Zhao LH, Li S, Wang WH. Unexplained infertility patients have increased serum IL-2, IL-4, IL-6, IL-8, IL-21, TNFalpha, IFNgamma and increased Tfh/CD4 T cell ratio: increased Tfh and IL-21 strongly correlate with presence of autoantibodies. Immunol Investig. 2015;44(2):164-73.

34. Barnhart K, Dunsmoor-Su R, Coutifaris C. Effect of endometriosis on in vitro fertilization. Fertil Steril. 2002;77(6):1148-55.

35. Cassini MA, Pilloni A, Condo SG, Vitali LA, Pasquantonio G, Cerroni L. Periodontal bacteria in the genital tract: are they related to adverse pregnancy outcome? Int J Immunopathol Pharmacol. 2013;26(4):931-9.

36. Chen X, Zhang Y, Lu HX, Feng XP. Factors associated with halitosis in white-collar employees in Shanghai, China. PLoS One. 2016;11(5):e0155592.

37. Zellmer M, Gahnberg L, Ramberg P. Prevalence of halitosis in elderly living in nursing homes. Int J Dent Hyg. 2016;14(4):295-300.

38. Lima PO, Calil CM, Marcondes FK. Influence of gender and stress on the volatile sulfur compounds and stress biomarkers production. Oral Dis. 2013;19(4):366-73.

39. Iwakura M, Yasuno Y, Shimura M, Sakamoto S. Clinical characteristics of halitosis: differences in two patient groups with primary and secondary complaints of halitosis. J Dent Res. 1994;73(9):1568-74.

\section{Publisher's Note}

Springer Nature remains neutral with regard to jurisdictional claims in published maps and institutional affiliations.

Ready to submit your research? Choose BMC and benefit from

- fast, convenient online submission

- thorough peer review by experienced researchers in your field

- rapid publication on acceptance

- support for research data, including large and complex data types

- gold Open Access which fosters wider collaboration and increased citations

- maximum visibility for your research: over 100M website views per year

At BMC, research is always in progress.

Learn more biomedcentral.com/submissions 